\title{
Biotechnology in Health Education: Healthy Lifestyles
}

\section{Maria del Carmen Ortega-Navas}

Faculty of UNED, Department of Theory of Education and Social Pedagogy, Spain

Corresponding author: Maria del Carmen Ortega-Navas, Makerere, Faculty of UNED, Department of Theory of Education and Social Pedagogy, Spain, Tel: 91398 8873; E-mail: cortega@edu.uned.es

Received: Nov 06, 2015; Accepted: Dec 29, 2015; Published: Jan 02, 2016

Copyright: @ 2016 Ortega-Navas MC. This is an open-access article distributed under the terms of the Creative Commons Attribution License, which permits unrestricted use, distribution, and reproduction in any medium, provided the original author and source are credited.

\section{Introduction}

The interest in our current and future eating habits is growing. The use of the new technologies, especially biotechnology, is being introduced in the food sector and becoming as a new food culture.

Biotechnology is a new concept recently installed. Biotechnology is the result of the union of two words: biology and technology. Biotechnology is not considered in itself as a science but as a multidisciplinary area that includes knowledge of the application of scientific principles and applied sciences (such as biology, chemistry, engineering and genetics, etc.) with high use in agriculture, pharmacy, food science, forestry and medicine, and processing of materials by biological agents to provide goods and services which allows to get a benefits for human being.

There are many definitions of biotechnology. Probably the first to use this term biotechnology was due to the Hungarian agricultural engineer [1] Károly Ereky, considered by some the "father" of biotechnology, who introduced in 1919 in his book, Biotechnologie der Fleisch-, Fett-, und Milcherzeugung im landwirtschaftlichen Grossbetriebe: für naturwissenschaftlich gebildete Landwirte verfass, due to his observations and new views about the source of a variety of apparently uses of the word biotechnology. He described biotechnology as the science of methods for obtaining products from raw materials, through the intervention of living organisms [2].

In 1992, the Convention on Biological Diversity has defined Biotechnology as "any technological application that uses biological systems, living organisms or derivatives to make or modify products or processes for specific use" (article 2. Use of Terms) [3].

To sum it is understood that biotechnology is a tool that allows you to apply and take advantage of the extensive knowledge of various sciences such as genetics, biology, medicine, chemistry, physiology and engineering among others.

\section{Historical Background}

In ancient times, men do not understand and be aware of how these processes occur or knew of microorganisms, and used them to their advantage. These applications constitute what is known as traditional biotechnology, which is based on the collection and use of the products of the metabolism of certain microorganism. Primitive ancestors, during the Stone Age, used living organisms and their products when they started to keep domestic animals and grow plants for food, rather than relying solely on what they could hunt or gather.

But really, the first people to use biotechnology were the Sumerians 7,000 years ago. They produced foods such as beer, wine, bread, yogurt and cheese using fermentation bioprocess (use of bacteria and yeasts that processed milk and transform it into yogurt and cheese or processed grapes or barley and transform into wine or beer).

With the discovery of DNA in 1953, Watson and Crick set the stage for a new era of biotechnology, known as "modern biotechnology", which began in 1973, when Cohen and colleagues conducted the first experiments in genetic recombination.

Resulting from the 70s becomes the development of genetic engineering, which allows you to modify and transfer genes from one organism to another, obtaining what is known as a transgenic organism or genetically modified organism (GMO).

In 1982 insulin is produced, as the first hormone derived from the application of biotechnology. In 1983 transgenic foods (Genetically modified-GM) and its use in the United States are approved. In Spain, we consider that modern biotechnology began to develop with the creation of the National Center for Biotechnology, in 1984, set in the program mobilizing biotechnology. In 2004 United Nations and Chile organized the first Global Biotechnology forum. Further, in Montreal 2009 was held the Sixth Annual World Congress on Industrial Biotechnology and Bioprocessing.

\section{Applications Fields}

The applications of Biotechnology can be found in different areas. This has prompted the need to create a classification system based on colors. Then briefly we present this classification:

- Red or healthcare biotechnology is applied to medical and food science processes. Includes molecular diagnostic techniques, development of vaccines, antibiotics and new drugs, production of biological molecules for therapeutic purposes (such as hormones and antibodies) gene therapy 
(modification of the genetic material of cells for treating diseases or disorders), transgenic animals as bioreactors (production of pharmacological proteins in milk of farm animals). For example, the development of generic engineering to cure diseases.

- White or industrial biotechnology is applied to industrial processes that use less resource than traditional processes used to produce industrial goods, aiming to replace polluting technologies for clean ones, using living organisms and their enzymatic systems. For example, the use of enzymes in detergents to reduce the use of other harmful ingredients for the environment and the new perfumes and cosmetics based on natural processes and solutions.

- Green or vegetal biotechnology is applied to agricultural processes. It uses for obtaining new features such as resistant to diseases and certain environmental factors, better nutrition of medical, biomedical or industrial interest. Other applications are: tissue culture and molecular biology, design of transgenic plants are able to grow under adverse environmental conditions and pest and disease resistant plants.

- $\quad$ Blue or marine biotechnology is based on the use of marine and aquatic organisms to the search for new substances that are used in various industries, such as food and medicines, as well as for the conservation of the environment.

- $\quad$ Gray or environmental biotechnology is oriented to applications related to environment. It can be divided into two main branches: the maintenance of biodiversity (for example cloning techniques to preserve species) and the elimination of pollutants using microorganisms and plant species (bioremediation).

\section{Red or Healthcare Biotechnology/ Green or Vegetal Biotechnology}

In the field of health, biotechnology achieved significant progress in what is medicine and agriculture among others, as for example in the production of transgenic foods (GM) that incorporate deficient nutrients in the diet of the population as vitamins or the elimination or reduction of problems of intolerance, toxicity and allergies.

Red biotechnology, as we mentioned above, is the use of altered genetic microorganisms for the production of substances like insulin, antibiotics, vitamins, vaccines and proteins for medical use, and is thus related to medical procedures. It provides examples labelled the help of genetic engineering to reduce disease transmission from new vaccines.

The biotechnology companies active in the health sector are mainly developing products for human health, both in development of biotech drugs and the development of products or services for the molecular diagnostics for the treatment or prevention of disease.
On the other hand, the green biotechnology is starting to be used to improve our food as a new genetic technique. Among the applications of green biotechnology we find distinct areas and of one of them is precisely the Food-Biotechnology, which is using techniques, and processes that use living organisms or substances to produce or modify a food and improve plants or animals from which they come, in order to a better life quality.

\section{Biotechnology and Food}

The global demand for food has increased the need for improved crops. Biotechnology is needed to produce more nutritious and better tasting food, higher crop yields and plants naturally protect against disease, insects and adverse conditions.

Besides, the Food Biotechnology uses techniques to produce or modify a food, from organisms living substance or develop microorganisms involved in its preparation, such as functional foods, are those who without therapeutic capacity, improve health or prevent against certain diseases.

Although, they are more present in many daily foods, for example probiotics, what is changing in the food industry is that, today, we want what we eat keeps our energy constant and satisfies our sensory appetites, but we also intend to be beneficial to our health.

In addition, today, we talk about different kinds of food such as: probiotics, nutraceutical and biotech (GM). Probiotics are those which have high content lactobacilli that help keep our healthy intestinal flora. These types of food help to reduce allergies and stimulate the immune response. As an example, Lactobacillus casei strengthens our immune system; it is useful in preventing childhood diarrhoea and ideal for those suffering from lactose intolerance. Nutraceutical foods are defined all those compounds or natural substances with a preventive and therapeutic action. For example: red grapes, broccoli, soy, red wine, goat milk, etc. botanical extracts: ginseng, garlic oil. Transgenic foods (GM) are those that have been produced from a genetically engineered organism and are incorporated genes from another organism to produce the desired characteristics. Currently they have a greater presence of food from transgenic plants such as corn or soybeans, golden rice, potatoes, pumpkin wheat, canola and grapes.

\section{Benefits and Risks}

The new developments of food that still common foods containing live microorganisms that ingested can provide numerous benefits or risks to our body arise. One of the advantages of genetically modified foods is the nutritional improvements. They can make genetic modifications to obtain enriched in essential amino acids, foods with modified fatty acid content, and foods with high solids content or enriched in certain vitamins or minerals, including nutritional quality characteristics of foods. Besides they help to raise food with fewer resources, fewer pests and diseases through genetically modified organism (GMO), reduce of pesticides and herbicides and damages health and the environment, improve nutrition 
of extra vitamins and proteins in foods and reducing natural toxins.

By contrast, some of the risks it brings to our wellbeing and health are the following ones: transferring toxins from one life form or transferring allergenic compounds from one species to another that could result in unexpected allergic reactions, exhaust from viruses and bacteria and infection of populations, harmful effects on the health of people taking genetically modified (GM) without consulting its components: example: GM food high in iron and antibiotic resistance of GM food (although there is no scientific evidence yet certain).

\section{Healthy lifestyles}

The debate about the influence of healthy eating for health is an issue highly discussed in health and education areas. Also, it notes that more and more people are acquiring healthier eating habits, given the growing concern about healthy food, giving way to the ideal of a healthy diet to an optimal diet. A good nutrition is important for good health in all stages of life: ages from early age to help with better quality of life in adulthood. For example, it has been shown in epidemiological studies, increased consumption of vegetables and/or fruit, boosting consumption of the Mediterranean diet reduces the risk of lung cancer, esophagus, stomach and colon.

The intake of functional foods is becoming more relevant in countries, developed, mainly due to the lifestyle and the growing acceptance of the direct influence of dietary habits on health. Besides, the trend toward healthy eating becomes ever stronger, as evidenced by numerous research related to healthy eating habits [4-7].

The lifestyles refers the set of behaviors that share a social group in connection with the living conditions and cultural patterns of that group, so reference lifestyles of people and the conditions in which they live and work strongly influence in health and longevity [8].

According to Ferry [9] the food contributes to fight disease and slow aging, since we "are what we eat, as the physical and mental vitality, mood and brainpower depends on what you eat"

\section{Conclusions}

The use of modern biotechnology in the field of health (gene therapy, nanotechnology, etc.) is viewed positively by most consumers but others are reluctant to accept transgenic food (GM). So the debate between those who support this type of food and detractors is open.

The possibility offered by the "modern biotechnology" is presenting new systems to modify the genetic properties of organisms in a way fully addressed.
Certainly Biotechnology (especially modern) means and can mean a breakthrough in the field of health and nutrition of the population and environmental protection. However, without going into details as it would require, this particular discipline raises ethical debates about genetic engineering and GMOs. Therefore, is why it is important and essential that society has access to all information concerning the methods used and possible risks or consequences of biotechnology, and that a rigorous control of this activity.

In general, some of the current benefits of using "biological technology" for our well-being are: more nutritious foods, improved taste and food quality, disease resistance, herbicide tolerance, reduced use of pesticides and fastest growing crops. Besides, the future benefits headed towards the emergence of appearance simpler and faster methods to detect: pathogens, toxins and pollutants, extension of the freshness of food and reduced levels of natural toxins such as allergens in plants.

In summary, the biotechnology in the field of health seeks to improve food for: kill or inhibit the presence of food allergens, add nutritional value, remove anti nutrient substances of certain foods, reduce or eliminate exposure to pathogens or toxins produced by them, to generate more efficient and sustainable cultivation and production of functional foods with beneficial effects prevention and treatment of certain diseases.

\section{References}

1. Fári MG, Kralovánszky UP (2006) The founding father of biotechnology: Károly (Karl) Ereky. International Journal of Horticultural Science12: 9-1.

2. Ereky K (1919) Biotechnologie der Fleisch-, Fett-, und Milcherzeugung im landwirtschaftlichen Grossbetriebe : fu" $r$ naturwissenschaftlich gebildete Landwirte verfasst. Berlín: Parey.

3. United Nation (1992) Convention on Biological Diversity.

4. Grenwald P, Clifford CK, y Milner JA (2001) Diet and cancer prevention. European Journal of Cancer 37: 948-065.

5. Cabo Soler JR (2007) Dieta y longevidad saludable. Revista Alimentación. Nutrición, Salud 14: 47-58.

6. Heinrich M, Prieto JM (2008) Diet and healthy ageing 2100: will we globalise local knowledge systems? See comment in PubMed Commons below Ageing Res Rev 7: 249-274.

7. Muntane MD (2009) Dietética antiaging y anticáncer. Madrid: Díaz de Santos.

8. Ortega Navas MC (2011) La salud y su perspectiva holística. En R. Perea. Educación para la salud y calidad de vida, Madrid: Díaz de Santos 25-46.

9. Ferry M (2008) Bases nutritionnelles pour un vieillissement réusi. Cahiers de Nutrition et de Dietétique 43: 90-96. 